\title{
Improving maternal, infant and young child nutrition in Nepal via peer mobilization
}

\author{
Akriti Singh ${ }^{1, *}$, Rolf DW Klemm ${ }^{2,3}$, Gary Mundy ${ }^{4}$, Pooja Pandey Rana ${ }^{5}$, Bhim Pun ${ }^{5}$ and \\ Kenda Cunningham ${ }^{5}$ \\ ${ }^{1}$ Friedman School of Nutrition Science \& Policy, Tufts University, 150 Harrison Avenue, Boston, MA 02111 , USA: \\ ${ }^{2}$ Helen Keller International, Washington, DC, USA: ${ }^{3}$ Johns Hopkins Bloomberg School of Public Health, Baltimore, \\ MD, USA: ${ }^{4}$ Helen Keller International, Phnom Penh, Cambodia: ${ }^{5}$ Helen Keller International, Kathmandu, Nepal
}

Submitted 9 November 2016: Final revision received 28 August 2017: Accepted 4 September 2017: First published online 6 November 2017

\begin{abstract}
Objective: To evaluate the impact of a peer facilitator (PF) approach for improving mothers' knowledge and practices relating to maternal and child nutrition.

Design: A quasi-experimental design nested within a large-scale integrated nutrition programme, Suaahara, in Nepal. Suaabara interventions were implemented in all study sites, but peer facilitators were used in only half of the study sites.

Setting: Rural, disadvantaged villages in three districts of Nepal: Bhojpur, Bajhang and Rupandehi.

Subjects: Mothers of children aged 6-23.9 months ( $n$ 1890).

Results: Differences over time between comparison (C) and intervention (I) groups show that the PF approach had a significant positive impact on several indicators of mothers' knowledge and practices relating to maternal and child nutrition: (i) knowing that fruits and vegetables are good for children 6-23.9 months (C: -0.7 , I: $10 \cdot 6 ; P=0.03$ ); (ii) child dietary diversity (C: 0.02 , I: $0.04 ; P=0.02$ ); (iii) child minimum dietary diversity ( $\geq 4$ of 7 food groups; (C: 6.9 , I: $16 \cdot 0 ; P=0.02$ ); (iv) maternal dietary diversity (C: 0.1 I: $0.4 ; P=0 \cdot 01$ ); and (v) maternal minimum dietary diversity ( $\geq 4$ food groups; C: $3 \cdot 6$, I: $14 \cdot 0 ; P=0 \cdot 03$ ). Additionally, exposure to a PF three or more times in the past 6 months was positively associated with a small improvement in maternal $(\beta=0.06, P=0.04)$ and child $(\beta=0.06, P=0.02)$ dietary diversity scores. Improvements were not observed in maternal healthseeking behaviours such as number of antenatal care visits.

Conclusions: Peer mobilization is a potential approach for improving health- and nutrition-related knowledge and behaviours among women in hard-to-reach communities of Nepal.
\end{abstract}

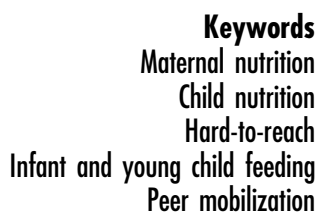

words

Child nutrition ng child feeding Peer mobilization
Community health workers have played a pivotal role in ensuring further reach of health and nutrition services in many low- and middle-income countries ${ }^{(1,2)}$. Despite current technological innovations, trained individuals interacting in person with community members remains an important avenue for the delivery of behaviour change communication strategies in resource-poor settings ${ }^{(3)}$. The role of these individuals, whether paid or voluntary, becomes even more critical in efforts to improve access to and utilization of health services among unreached populations, the importance of which has recently resurfaced.

Nepal, a low-income country in South Asia with a population of 27 million, has historically been a global success in the implementation of community-based health programmes, not only due to community health workers (e.g. village health workers, auxiliary health workers) but also in large part due to the development of a cadre of about 50000 female community health volunteers (FCHV), starting in the late $1980 \mathrm{~s}^{(4,5)}$. Given the challenges of difficult terrain and geographically remote and isolated communities in Nepal, the FCHV system was created to increase access to health services in those communities. In particular, FCHV provide health and nutrition counselling and services to women of reproductive age and children under the age of 5 years, such as vitamin A supplementation, iron and folic acid supplementation, contraceptives, and community-based integrated management of childhood illnesses ${ }^{(6,7)}$. FCHV are well-respected, married women selected by the health mothers' group of 
reproductive age women in each ward, the smallest administrative unit. The most recent nationally representative survey of FCHV revealed that these volunteers are on average 41 years of age, with $67 \%$ of them having attended some formal schooling $^{(7)}$. It is estimated that one FCHV is responsible for 156-706 households ${ }^{(4)}$. Nepal's FCHV programme received international recognition for the volunteers' role in the success of the National Vitamin A Program, which led to more community-based programming responsibilities delegated to them over time ${ }^{(8)}$. The role of FCHV as an effective delivery platform for community-based nutrition interventions cannot be doubted. These trained and dedicated individuals, aware of community-specific norms and challenges, assist women and their families overcome barriers to optimal maternal, infant and young child nutrition (MIYCN) practices.

Although Nepal has made significant progress in reducing child undernutrition in recent years, national-level indicators show that much work remains to be done to improve MIYCN practices in Nepal: $66 \%$ of children under the age of 6 months are exclusively breast-fed, $42 \%$ of mothers took iron and folic acid tablets for at least $180 \mathrm{~d}$ during the last pregnancy, and $69 \%$ of mothers received four or more antenatal care visits during their last pregnancy ${ }^{(9)}$. The burden of undernutrition remains higher among those in the lowest wealth quintile ${ }^{(9,10)}$. The Government of Nepal categorizes each village development committee (VDC), comprised of nine wards, based on its concentration of socially and geographically excluded populations using a set of pre-established criteria for disadvantaged group (DAG) mapping. For this purpose, seven criteria are used: (i) food sufficiency for less than 3 months; (ii) marginalized groups (e.g. Dalits, Janjatis); (iii) poor access to primary education; (iv) low access to health posts; (v) low participation of women, Dalits and Janjatis in decision making; (vi) prevalence of gender discrimination; and (vii) prevalence of vulnerable groups ${ }^{(11)}$.

Suaahara, an integrated nutrition programme implemented in forty-one out of seventy-five districts of Nepal from 2011 to 2016, worked with FCHV to deliver community-level interventions to improve household awareness of and behaviours related to: nutrition; health; family planning; water, sanitation and hygiene; and homestead food production including home gardening and backyard poultry; as well as issues related to gender equity and social inclusion. Suaahara's process evaluation showed improvements in MIYCN knowledge and some practice indicators in Suaahara districts compared with comparison districts that did not receive programme inputs. Furthermore, the gap between disadvantaged households and nondisadvantaged households was smaller in Suaabara districts than comparison districts ${ }^{(12)}$. Monitoring data of the homestead food production component showed that elements of the programme (chicks, technical support, beneficiary groups) were positively associated with maternal and child diet diversity ${ }^{(13)}$. Almost two years into programme implementation, monitoring data revealed a limitation in programme coverage. Since FCHV are volunteers with a considerable workload, Suaahara considered the use of a peer model as a way of engaging additional community members to support in health- and nutrition-related behaviour change efforts.

A recent systematic review ( $n$ 47) highlighted the effectiveness of peer support models for improving health outcomes $^{(14)}$. Global evidence also shows the effectiveness of peer support in nutrition programming, particularly for promotion of optimal breast-feeding practices ${ }^{(15-17)}$ and increasingly for complementary feeding as well ${ }^{(18,19)}$. In Nepal, HIV/AIDS and adolescent health programmes have used peer support, but the mobilization of peers to provide support for MIYCN has yet to be explored or studied $^{(20)}$. Based on this evidence, Suaahara piloted a peer facilitator (PF) approach in some intervention areas: PF were to work in close collaboration with the government health infrastructure, including FCHV, to reinforce important MIYCN messages. This intervention, and the evaluation of it, aimed to assess the effectiveness of a peer support approach for improving MIYCN-related knowledge and practices among mothers of young children.

\section{Methods}

\section{Intervention design}

Suaabara piloted the PF approach to increase the reach of MIYCN messages to $1000 \mathrm{~d}$ women, defined as the period between conception and a child's second birthday, living in remote DAG VDC.

In May 2014, a consultation meeting was organized with the District Health Offices, health facility staff and FCHV of selected VDC in four Suaahara districts: Bajhang, Bhojpur, Rupandehi and Sindhupalchok, to select PF based on predetermined criteria (Fig. 1). The selection criteria for PF included: (i) living in a geographically remote ward in a DAG VDC where frequent FCHV reach was challenging; (ii) willingness to volunteer to promote optimal MIYCN behaviours in their ward; and (iii) having at least one child under 2 years of age. Districts were selected to include at least one from each of Nepal's three agroecological zones: mountains, hills and terai.

After selection, PF received training on key MIYCN messages in three sessions spaced one month apart to provide information incrementally, an opportunity to clarify concepts and space for experience sharing among PF. The total length of the three modules was $4 \mathrm{~d}$ (module 1 was $2 \mathrm{~d}$ long). PF were also given a picture book with MIYCN messages to help them remember the messages and to use as a visual aid while talking to women in their communities. The main roles of PF were to: (i) increase awareness of health and nutrition services provided by health facilities (e.g. antenatal care and postnatal care check-ups) and by FCHV (e.g. iron and folic acid supplements); and (ii) remind peers of optimal health and nutrition behaviours pertinent to 


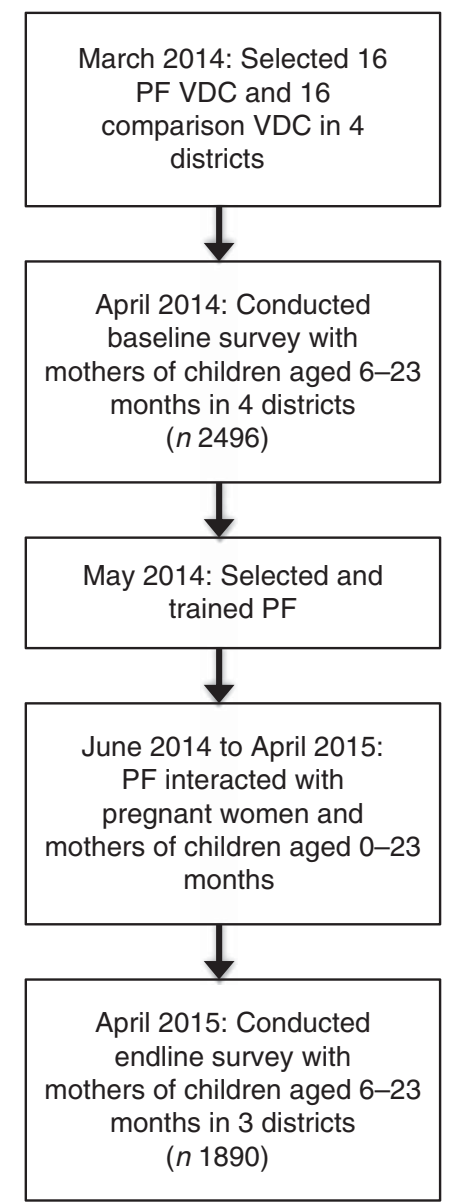

Fig. 1 Timeline of the PF intervention and impact evaluation (PF, peer facilitator; VDC, village development committee)

pregnancy (e.g. eating one more meal than usual), lactation (e.g. eating two more meals than usual) and children under 2 years of age (e.g. breast-feeding initiation, diversity in complementary foods).

One PF was responsible for no more than fifteen households. To reduce workload for PF who were volunteering their time, Suaahara did not require PF to track the number of people they met or shared MIYCN messages with, but encouraged them to disseminate their knowledge as widely as possible. Following their $4 \mathrm{~d}$ training, two review meetings were organized one month apart and PF were also encouraged to attend the FCHV's monthly health mothers' group meetings. Suaahara staff in collaboration with health facility staff trained the PF. For their time and effort, PF received the same amount of cash FCHV receive for attending trainings, but no further financial incentives were provided so as to enable testing of a potentially sustainable approach. During review meetings, PF shared the number of interactions they had with peers and discussed challenges encountered and potential ways to overcome these challenges; however, this information was not recorded to keep the volunteering time required by PF minimal.

\section{Evaluation design}

A quasi-experimental impact evaluation design was used to assess the impact of the PF approach (see Fig. 2). Within Suaahara districts, PF intervention and comparison (nonPF) areas were selected. Cross-sectional household-level baseline and endline surveys were conducted 12 months apart in three Suaahara districts (Bhojpur, Bajhang and Rupandehi) in both PF and non-PF areas, among households with children aged 6-23.9 months. One district was excluded from the endline survey, and hence the current analysis, due to the earthquakes of 2015.

\section{Sampling}

To determine the sample size, consumption of foods from at least four of seven food groups by children aged 6-23.9 months, an infant and young child feeding indicator to be targeted directly by PF, was used. Suaahara monitoring data showed that the weighted average of this indicator was $50.5 \%$ in districts sampled by this survey. Using this value, a sample size of 1215 in each group would detect a change of $6 \%$ at endline with a power of $90 \%$ and a level of confidence of $95 \%$ for a one-sided $t$ test. To enable equal distribution at the ward level, the sample size was increased to 2496 total.

Multistage cluster sampling was used with the first sampling unit as districts ( $n$ 4), selected because they were intervention districts, covering Nepal's diverse agroecological zones. The second sampling unit was VDC ( $n$ 32; eight VDC per district: four intervention VDC and four comparison VDC). The third sampling unit was wards ( $n$ 96; three wards per VDC) and the final sampling unit was households with children aged 6-23.9 months ( $n$ 2496; twenty-six per ward). The PF intervention areas were selected by marking all DAG VDC of category 3A, 3B and 4 on a map of the district. The district was then divided into four quadrants and probability proportional to size was used to select one PF VDC in each of the quadrants: four PF VDC per district. Since PF were only to be used in four VDC per district, wards were randomly selected for the survey in each of those VDC. Matched comparison VDC were selected, in consultation with local government officials, in terms of remoteness, DAG categorization and receipt of other Suaahara inputs. Wards within the comparison VDC were randomly selected as well.

For selection of the twenty-six households in each ward, enumerators created a map to identify and number distinct settlements. In each segment, the enumerators chose a random number to select which segment to use to start screening households for meeting the study inclusion criteria: a mother with at least one child between 6 and 23.9 months of age living in the household. If the household had more than one eligible mother in the household, the enumerators randomly selected one mother. Also, if the selected mother had more than one child in the study age range, the youngest child was selected. If there were 


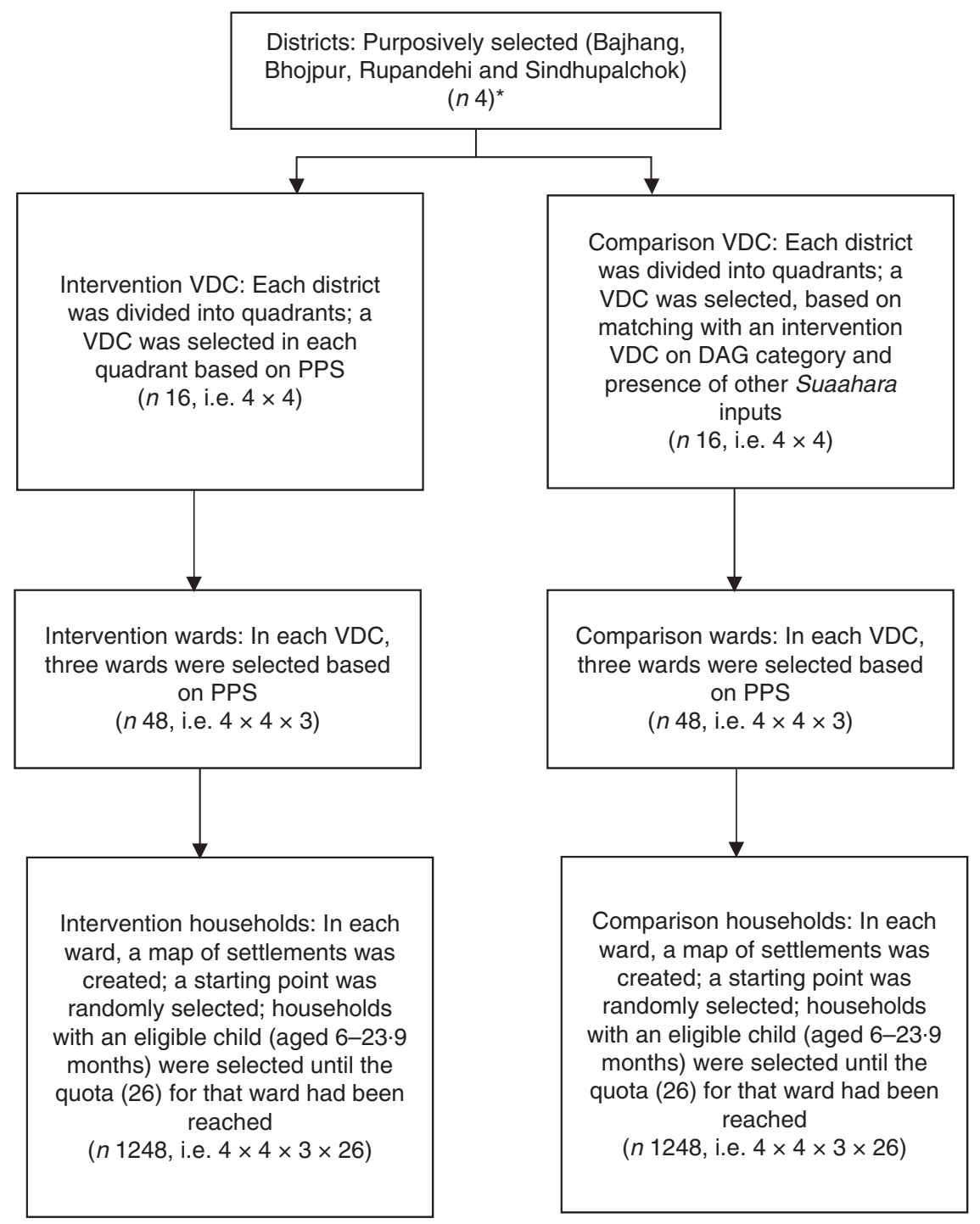

Fig. 2 Peer facilitator sampling strategy. *Sample size calculation was based on four districts, but analysis was restricted to three districts which had data available for two time points (VDC, village development committee; PPS, probability proportional to size; DAG, disadvantaged group)

not twenty-six eligible households in the ward, then enumerators sampled in the adjoining ward.

\section{Data collection}

Valley Research Group (VARG), an external research firm, conducted both baseline (April-May 2014) and endline data collection (May-June 2015). Enumerators received $5 \mathrm{~d}$ of training and the survey covered topics such as: background characteristics; infant and young child feeding, and child health; maternal diet and health, including antenatal care, delivery and postnatal care; family planning; empowerment; and water, sanitation and hygiene. It included $24 \mathrm{~h}$ dietary recalls for both the mother and child, as per standard WHO guidelines ${ }^{(21)}$. The survey questionnaires were developed in English, translated to Nepali and back-translated to English to ensure accuracy and completeness. The questionnaires were also pre-tested prior to data collection. VARG administered paperbased surveys at baseline and these data were entered, cleaned and checked using CSPro. Double data entry was conducted to ensure data quality. At endline, data were collected electronically (mobile phones) and uploaded to a server daily. These data were available for checking and cleaning in Excel before being saved as STATA data files for analysis.

\section{Analysis}

For the present study, we assessed four key MIYCN outcomes among mothers: (i) child nutrition knowledge; (ii) maternal nutrition knowledge; (iii) child nutrition practices; and (iv) maternal nutrition practices. Only messages the PF were trained and expected to deliver were included in this set of analyses. For each of the indicators, indices were created. Breast-feeding indicators were constructed only for children less than 12 months of 
age, as the mothers of older children could not have been exposed to a PF at the time when the child should have received colostrum and initiated breast-feeding. Child diet diversity was constructed only among children aged 7-23.9 months. Maternal practice indicators other than dietary diversity were constructed only for mothers of children less than 12 months of age as only these mothers would have been exposed to the PF during pregnancy and postpartum periods. Analyses of breast-feeding and maternal practice indicators other than diet diversity were further restricted only to children 6 months of age when assessing exposure to PF in the past 6 months. All dietary diversity indicators were based on a qualitative $24 \mathrm{~h}$ recall. The indices below were constructed by adding the following components for each index.

- Child nutrition knowledge: (i) precisely defining exclusive breast-feeding as providing only breast milk not even water until 6 months; (ii) reporting that consumption of animal-source foods (flesh foods eggs, or dairy products) by children aged 6-23.9 months is good for the child's nutrition; and (iii) reporting that consumption of fruit and vegetables by children aged 6-23.9 months is good for the child's nutrition.

- Maternal nutrition knowledge: (i) precisely reporting that pregnant women should eat one more meal per day than usual; (ii) precisely reporting that pregnant women should take iron and folic acid supplementation for $180 \mathrm{~d}$; and (iii) precisely reporting that lactating women should eat two more meals per day than usual.

- Child nutrition practices: (i) fed colostrum; (ii) breast-fed within $1 \mathrm{~h}$ of birth; (iii) child dietary diversity ( $0-7$ food groups); and (iv) child minimum dietary diversity (at least 4 out of 7 food groups). The seven food groups were: grains, roots and tubers; legumes and nuts; dairy products; flesh foods (meat, fish, poultry and liver/ organ meats); eggs; vitamin A-rich fruits and vegetables; and other fruits and vegetables ${ }^{(21)}$.

- Maternal nutrition practices: (i) consumption of one extra meal while pregnant; (ii) consumption of two extra meals while lactating; (iii) at least four antenatal care visits; (iv) at least three postnatal care visits; (v) iron and folic acid consumption for at least $180 \mathrm{~d}$ during pregnancy; (vi) iron and folic acid consumption for at least $45 \mathrm{~d}$ post-delivery; (vii) dietary diversity (0-9 food groups); and (viii) maternal minimum dietary diversity (at least 4 out of 9 food groups). The nine food groups were: grains, roots and tubers; legumes and nuts; dairy products; meat; eggs; fish; dark green leafy vegetables; vitamin A-rich fruits and vegetables; and other fruits and vegetables $^{(22)}$.

Data analysis was conducted using the statistical software package STATA version 13. Differences at baseline and endline between the PF and comparison groups were assessed using clttest (for continuous outcomes) and clchi2 (for categorical outcomes) to take ward-level clustering into account. Impact analyses were conducted using double difference estimation between the PF and comparison groups over the two survey rounds, adjusting for ward-level clustering, as well as potentially confounding factors related to geography, household, maternal and child characteristics. Linear regression analysis was used to assess the effect of frequency of meeting the PF in the 6 months prior to the survey (endline) and maternal and child knowledge and practice indices (or indicator) among respondents in $\mathrm{PF}$ intervention areas. Poisson regression was used to analyse dietary diversity indicators. This model was also adjusted for the same factors as the double difference models. Statistical significance was defined as $P<0 \cdot 05$.

\section{Results}

\section{Respondent characteristics}

Table 1 shows the background characteristics of respondent mothers and their children aged 6-23.9 months at baseline and endline. There were no differences in background characteristics between the PF intervention and comparison groups at baseline. Similarly, there were no differences in these characteristics at endline, except that mothers in the PF intervention group at endline tended to be slightly older than mothers in the comparison group (I: 26 years; C: 25 years; $P=0 \cdot 018$ ).

\section{Suaahara exposure}

Table 2 shows exposure to the $\mathrm{PF}$ at endline in PF intervention areas, including frequency, location and type of interaction respondents had with the PF. More than $70 \%$ of the respondents had met a PF at least once. More than half of the PF were in the $1000 \mathrm{~d}$ period (47\%). In the 6 months prior to the endline survey, respondents met the $\mathrm{PF}$ on average two times, with most interactions occurring during community-level activities. Most respondents reported that during their most recent interaction with the $\mathrm{PF}$, the discussions and activities related to child health/nutrition (88\%), followed by maternal health/ nutrition (52\%) and water, sanitation and hygiene (31\%). Very few respondents reported that the PF talked to them about Suaahara's radio programme, Bhanchbin Aama. A small number of respondents shared that the PF spoke to other family members (16\%), but many reported that the PF used materials such as the handbook ( $74 \%)$ and that they found interactions with the PF to be helpful (78\%).

\section{Impact on maternal knowledge}

Table 3 shows the impact of the PF on maternal knowledge and practices related to maternal and child nutrition. Knowing that fruits and vegetables are good for children aged 6-23.9 months (I: 74-84\%; C: 75-74\%; $P=0.026$ ) decreased in the comparison group, but increased in the 
Table 1 Background characteristics of respondents at baseline and endline: mothers of children aged 6-23.9 months ( $n$ 1890) in rural, disadvantaged villages in three districts of Nepal, April-May 2014 (baseline) and May-June 2015 (endline)

\begin{tabular}{|c|c|c|c|c|c|c|c|c|c|c|}
\hline \multirow[b]{3}{*}{ Characteristic } & \multicolumn{4}{|c|}{ Comparison (C) } & \multicolumn{4}{|c|}{ PF intervention (I) } & \multirow{3}{*}{$\frac{\text { Baseline: } \mathrm{C} \text { v. I }}{P \text { value } \dagger}$} & \multirow{3}{*}{$\frac{\text { Endline: } \mathrm{C} v . \mathrm{I}}{P \text { value } \dagger}$} \\
\hline & \multicolumn{2}{|c|}{$\begin{array}{c}\text { Baseline } \\
\text { ( } n \text { 945) }\end{array}$} & \multicolumn{2}{|c|}{$\begin{array}{l}\text { Endline } \\
(n \text { 945) }\end{array}$} & \multicolumn{2}{|c|}{$\begin{array}{c}\text { Baseline } \\
\text { ( } n \text { 945) }\end{array}$} & \multicolumn{2}{|c|}{$\begin{array}{l}\text { Endline } \\
(n 945)\end{array}$} & & \\
\hline & Mean & SE & Mean & SE & Mean & SE & Mean & SE & & \\
\hline Child's age (months) & $14 \cdot 1$ & $5 \cdot 2$ & $14 \cdot 3$ & $5 \cdot 3$ & 14.5 & $5 \cdot 4$ & $13 \cdot 9$ & 5.5 & 0.107 & 0.154 \\
\hline Maternal age (years) & $26 \cdot 0$ & $5 \cdot 4$ & $25 \cdot 3$ & $5 \cdot 0$ & $26 \cdot 2$ & $5 \cdot 8$ & $26 \cdot 0$ & 5.4 & 0.639 & $0.018^{*}$ \\
\hline Maternal education (no. of completed grades) & $2 \cdot 7$ & 3.7 & 3.5 & $4 \cdot 0$ & 3.4 & $4 \cdot 1$ & 4.0 & $4 \cdot 1$ & 0.975 & 0.985 \\
\hline \multirow{2}{*}{\multicolumn{9}{|c|}{ Caste (\%) }} & 0.896 & 0.573 \\
\hline & & & & & & & & & 0.571 & 0.815 \\
\hline Dalit & \multirow{2}{*}{\multicolumn{2}{|c|}{$\begin{array}{l}15.6 \\
22.1\end{array}$}} & \multicolumn{2}{|c|}{$17 \cdot 7$} & \multicolumn{2}{|c|}{$16 \cdot 9$} & \multicolumn{2}{|c|}{18.2} & & \\
\hline Janjati & & & \multirow{2}{*}{\multicolumn{2}{|c|}{$\begin{array}{l}22.0 \\
38.0\end{array}$}} & \multicolumn{2}{|c|}{$23 \cdot 3$} & \multicolumn{2}{|c|}{23.4} & & \\
\hline Bahun/Chhetri & \multicolumn{2}{|c|}{38.7} & & & \multirow{2}{*}{\multicolumn{2}{|c|}{$\begin{array}{l}36 \cdot 4 \\
15.1\end{array}$}} & \multicolumn{2}{|c|}{$34 \cdot 3$} & & \\
\hline Other Madhesi Terai & \multicolumn{2}{|c|}{$15 \cdot 6$} & \multicolumn{2}{|c|}{$15 \cdot 1$} & & & \multirow{2}{*}{\multicolumn{2}{|c|}{$\begin{array}{r}16 \cdot 3 \\
3 \cdot 8\end{array}$}} & & \\
\hline Muslim & \multicolumn{2}{|c|}{$7 \cdot 2$} & \multicolumn{2}{|c|}{$6 \cdot 2$} & \multicolumn{2}{|c|}{3.5} & & & & \\
\hline Other & \multicolumn{2}{|c|}{0.9} & \multicolumn{2}{|c|}{1.0} & \multicolumn{2}{|c|}{4.8} & \multicolumn{2}{|c|}{4.0} & & \\
\hline Agroecological zone (\%) & \multirow{2}{*}{\multicolumn{2}{|c|}{33.3}} & & & & & & & NA & NA \\
\hline Mountain & & & \multicolumn{2}{|c|}{33.3} & \multicolumn{2}{|c|}{33.3} & \multicolumn{2}{|c|}{33.3} & & \\
\hline Hill & \multicolumn{2}{|c|}{33.3} & 33 & & 33. & & 33. & & & \\
\hline Terai & 33 & & 33 & & 33 & & 33 & & & \\
\hline
\end{tabular}

$\mathrm{PF}$, peer facilitator; NA, not applicable.

${ }^{*} P<0.05$.

†Controlled for ward-level clustering.

$\ddagger$ Assets: electricity, solar panel, bicycle, motorcycle, telephone/mobile, television, radio and refrigerator.

Table 2 Exposure to peer facilitators among mothers of children aged 6-23.9 months ( $n$ 945) in rural, disadvantaged villages in three districts of Nepal, May-June 2015 (endline)

\begin{tabular}{|c|c|}
\hline Characteristic & $\%$ \\
\hline Maternal BA listening frequency: $\geq 2$ times/month & 31.5 \\
\hline Maternal Suaahara-affiliated group participation: yes & $52 \cdot 2$ \\
\hline Ever met PF & 71.6 \\
\hline PF pregnant or with child under 2 years & $46 \cdot 8$ \\
\hline Among those who met PF in past 6 months & n 677 \\
\hline \multicolumn{2}{|l|}{ Number of times met PF } \\
\hline Mean & $2 \cdot 2$ \\
\hline SE & 1.4 \\
\hline \multicolumn{2}{|l|}{ Location of last meeting with PF } \\
\hline At health/HFP-mothers' group meeting & $24 \cdot 2$ \\
\hline Somewhere in ward & $23 \cdot 8$ \\
\hline At food demonstration & 21.9 \\
\hline At home (respondent's or PF's) & 14.9 \\
\hline Health facility/event & $10 \cdot 0$ \\
\hline While doing chores (e.g. collecting firewood, market) & $5 \cdot 2$ \\
\hline \multicolumn{2}{|l|}{ PF talked about during last meetingt } \\
\hline Child health/nutrition & $88 \cdot 0$ \\
\hline Maternal $r$ & $52 \cdot 1$ \\
\hline WASH (water purification, toilet use) & 30.9 \\
\hline Agriculture & $19 \cdot 7$ \\
\hline $\mathrm{BA}$ radio programme & $5 \cdot 8$ \\
\hline Other & 2.7 \\
\hline PF spoke with other family members during last meeting & $16 \cdot 2$ \\
\hline PF used materials (e.g. picture book) during last meeting & $74 \cdot 0$ \\
\hline Found meeting with PF helpful & 77.5 \\
\hline
\end{tabular}

BA, Bhanchhin Aama; PF, peer facilitator; HFP, homestead food production; WASH, water, sanitation and hygiene.

†Does not sum to $100 \%$ because multiple-response question.

PF intervention group. The double difference estimate was significant only for this indicator. All three indicators on maternal knowledge of maternal nutrition had baseline to endline increases in both the PF intervention and comparison groups; however, none of the double difference estimates were significant.

\section{Impact on maternal practices}

For practices relating to child nutrition, three indicators increased from baseline to endline in the PF intervention and comparison groups, but the double difference estimates were significant only for the indicators on diet diversity: dietary diversity (I: $3 \cdot 1-3 \cdot 5 ; \mathrm{C}: 3 \cdot 2-3 \cdot 4 ; P=0 \cdot 015$ ) and minimum dietary diversity (I: 33-49\%; C: 39-46\%; $P=0.021$ ). The mean difference in the diet diversity score between the two groups was modest at $0 \cdot 2$. For practices relating to maternal nutrition, there were improvements between baseline and endline in seven out of eight indicators for the PF intervention and comparison groups, with double difference estimates significant only for the indicators on diet diversity: diet diversity (I: 3.3-3.7; C: 3.5-3.6; $P=0.007$ ) and minimum dietary diversity (I: 39-53\%; C: $45-49 \% ; P=0.026)$.

\section{Exposure to a peer facilitator in past 6 months and knowledge and practice outcomes}

Table 4 shows positive and significant associations between the frequency of a mother meeting a PF in the 6 months prior to the endline survey and her knowledge and practices related to maternal and child nutrition, even after controlling for ward-level clustering and various maternal, child and household factors. In the adjusted models, relative to no exposure to a PF, increased exposure to a PF in the previous 6 months was associated with higher child nutrition knowledge (twice: $\beta=0.387$, 
Table 3 Maternal, infant and young child nutrition-related knowledge and practices, in intervention and comparison groups, from baseline to endline: mothers of children aged 6-23.9 months $(n$ 1890) in rural, disadvantaged villages in three districts of Nepal, April-May 2014 (baseline) and May-June 2015 (endline)

\begin{tabular}{|c|c|c|c|c|c|c|c|c|}
\hline \multirow[b]{3}{*}{ Characteristic } & \multicolumn{3}{|c|}{ Comparison $(\mathrm{C})$} & \multicolumn{3}{|c|}{ PF intervention (I) } & \multirow{3}{*}{$\begin{array}{c}\begin{array}{c}\text { Simple } \\
\text { model }\end{array} \\
\text { DID }\end{array}$} & \multirow{3}{*}{$\begin{array}{c}\begin{array}{c}\text { Full } \\
\text { model }\end{array} \\
\text { DID }\end{array}$} \\
\hline & $\begin{array}{l}\text { Baseline } \\
\text { (n 945) }\end{array}$ & $\begin{array}{l}\text { Endline } \\
(n 945)\end{array}$ & $\begin{array}{l}\text { Difference } \\
\quad(n 945)\end{array}$ & $\begin{array}{l}\text { Baseline } \\
(n 945)\end{array}$ & $\begin{array}{l}\text { Endline } \\
(n \text { 945) }\end{array}$ & $\begin{array}{l}\text { Difference } \\
\quad(n 945)\end{array}$ & & \\
\hline & $\%$ or mean, SE & $\%$ or mean, SE & $\%$ or mean, SE & $\%$ or mean, SE & $\%$ or mean, SE & $\%$ or mean, SE & & \\
\hline \multicolumn{9}{|l|}{ Child nutrition knowledge } \\
\hline Know baby should be given only breast milk for 6 months & 81.5 & 94.0 & 12.5 & 81.6 & $98 \cdot 0$ & $16 \cdot 4$ & $0 . .340$ & 0.354 \\
\hline Know animal-source foods are good for children aged $6-23.9$ months & 87.4 & $95 \cdot 0$ & $7 \cdot 6$ & $89 \cdot 2$ & $97 \cdot 0$ & $7 \cdot 8$ & 0.938 & 0.962 \\
\hline Know fruits and vegetables are good for children aged 6-23.9 months & 74.5 & 73.8 & -0.7 & 73.5 & $84 \cdot 1$ & $10 \cdot 6$ & $0.029^{*}$ & $0.026^{\star}$ \\
\hline \multicolumn{9}{|l|}{ Maternal nutrition knowledge } \\
\hline Know pregnant women should eat one extra meal & $42 \cdot 9$ & 65.5 & $22 \cdot 6$ & $45 \cdot 9$ & $59 \cdot 3$ & 13.4 & 0.189 & 0.084 \\
\hline Know pregnant women should take iron and folic acid for $180 \mathrm{~d}$ & $50 \cdot 1$ & 51.5 & 1.4 & $50 \cdot 6$ & $66 \cdot 3$ & $15 \cdot 7$ & 0.094 & 0.174 \\
\hline Know lactating women should eat two extra meals & 69.9 & $76 \cdot 8$ & $6 \cdot 9$ & 75.5 & $88 \cdot 2$ & $12 \cdot 7$ & 0.372 & 0.136 \\
\hline \multicolumn{9}{|l|}{ Child nutrition practices } \\
\hline $\begin{array}{l}\text { Fed colostrum, among 6-11-month-olds (all, } n \text { 1357; C, } n \text { 675; } \\
\text { I, } n 682 \text { ) }\end{array}$ & $96 \cdot 4$ & $96 \cdot 8$ & 0.4 & $95 \cdot 9$ & $97 \cdot 3$ & 1.4 & 0.653 & 0.735 \\
\hline $\begin{array}{l}\text { Breast-fed within } 1 \mathrm{~h} \text { of birth, among } 6-11 \text {-month-olds (all, } n 1357 \text {; } \\
\quad \text { C, } n 675 ; \mathrm{I}, n 682)\end{array}$ & $68 \cdot 1$ & $66 \cdot 8$ & $-1 \cdot 3$ & $67 \cdot 8$ & $77 \cdot 3$ & 9.5 & 0.191 & 0.205 \\
\hline $\begin{array}{l}\text { Dietary diversity (range: } 0-7 \text { food groups), among 7-23-month-olds } \\
\quad \text { (all, } n \text { 3532; C, } n \text { 1784; I, } n \text { 1748), mean }\end{array}$ & $3 \cdot 2$ & $3 \cdot 4$ & 0.2 & $3 \cdot 1$ & 3.5 & 0.4 & 0.057 & $0.015^{\star}$ \\
\hline SE & 1.2 & 1.2 & 0.0 & $1 \cdot 1$ & $1 \cdot 1$ & 0.0 & & \\
\hline $\begin{array}{l}\text { Minimum dietary diversity ( } \geq 4 \text { food groups), among 7-23-month-olds } \\
\quad \text { (all, } n \text { 3532; C } n \text { 1784; I, } n \text { 1748) }\end{array}$ & 38.9 & $45 \cdot 8$ & 6.9 & $32 \cdot 7$ & $48 \cdot 7$ & $16 \cdot 0$ & 0.057 & $0.021^{*}$ \\
\hline \multicolumn{9}{|l|}{ Maternal nutrition practices } \\
\hline Dietary diversity (range: $0-9$ food groups), mean & 3.5 & 3.6 & 0.1 & 3.3 & 3.7 & 0.4 & $0.008^{\star \star}$ & $0.007^{\star *}$ \\
\hline SE & 1.3 & $1 \cdot 1$ & -0.2 & $1 \cdot 1$ & 1.2 & $0 \cdot 1$ & & \\
\hline Minimum dietary diversity ( $\geq 4$ food groups) & $45 \cdot 0$ & 48.6 & $3 \cdot \overline{6}$ & $39 \cdot 1$ & $53 \cdot 1$ & 14.0 & $0.029^{*}$ & $0.026^{*}$ \\
\hline $\begin{array}{l}\text { Consumed one extra meal during pregnancy, among } 6-11 \text {-month-olds } \\
\quad \text { (all, } n 1357 ; \mathrm{C}, n 675 ; \mathrm{I}, n \text { 682) }\end{array}$ & $39 \cdot 1$ & $47 \cdot 1$ & $8 \cdot 0$ & $42 \cdot 0$ & $56 \cdot 7$ & 14.7 & 0.404 & 0.419 \\
\hline $\begin{array}{l}\text { Consumed two extra meals during lactation, among } 6 \text {-11-month-olds } \\
\quad \text { (all, } n 1357 ; \mathrm{C}, n 675 ; \mathrm{I}, n 682 \text { ) }\end{array}$ & $42 \cdot 7$ & $30 \cdot 0$ & $-12 \cdot 7$ & $43 \cdot 2$ & $44 \cdot 1$ & 0.9 & 0.156 & 0.181 \\
\hline $\begin{array}{l}\text { Antenatal care visits ( } \geq 4 \text { times), among } 6-11 \text {-month-olds (all, } n 1357 \text {; } \\
\quad \text { C, } n 675 ; I, n 682 \text { ) }\end{array}$ & $36 \cdot 1$ & $47 \cdot 7$ & 11.6 & 35.0 & 53.4 & 18.4 & 0.245 & 0.268 \\
\hline $\begin{array}{l}\text { Postnatal care visits ( } \geq 3 \text { times), among } 6 \text {-11-month-olds (all, } n 1357 \text {; } \\
\text { C, } n 675 ; I, n 682 \text { ) }\end{array}$ & 5.4 & $12 \cdot 9$ & 7.6 & $4 \cdot 1$ & 14.0 & 9.9 & 0.584 & 0.520 \\
\hline $\begin{array}{l}\text { Took iron and folic acid for at least } 180 \mathrm{~d} \text { during pregnancy, among } \\
6-11 \text {-month-olds (all, } n 1357 ; \mathrm{C}, n 675 ; \mathrm{I}, n \text { 682) }\end{array}$ & $36 \cdot 1$ & 46.5 & 10.4 & 39.4 & $60 \cdot 3$ & 20.9 & 0.175 & 0.215 \\
\hline $\begin{array}{l}\text { Took iron and folic acid for at least } 45 \mathrm{~d} \text { during lactation, among } \\
6-11 \text {-month-olds (all, } n \text { 1357; C, } n 675 ; \mathrm{I}, n \text { 682) }\end{array}$ & $26 \cdot 6$ & 34.4 & 7.8 & $26 \cdot 8$ & 42.5 & $15 \cdot 7$ & 0.284 & 0.373 \\
\hline
\end{tabular}

$\mathrm{PF}$, peer facilitator.; DID, difference in difference. Simple model controlled for ward-level clustering. Full model controlled for child's age, maternal age, education, household ownership of assets, caste, agroecological zone of residency and ward-level clustering. 


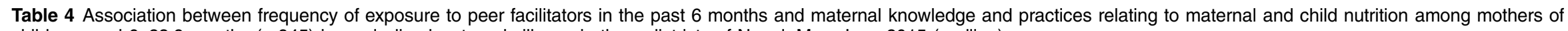
children aged 6-23.9 months ( $n$ 945) in rural, disadvantaged villages in three districts of Nepal, May-June 2015 (endline)

\begin{tabular}{|c|c|c|c|c|c|c|c|c|c|c|c|c|}
\hline & \multicolumn{2}{|c|}{$\begin{array}{l}\text { Child knowledge } \\
\text { index ( } n \text { 945) }\end{array}$} & \multicolumn{2}{|c|}{$\begin{array}{l}\text { Maternal knowledge } \\
\text { index ( } n \text { 945) }\end{array}$} & \multicolumn{2}{|c|}{$\begin{array}{l}\text { Child practice index } \\
\text { (child } 6 \text { months, } \\
n \text { 81) }\end{array}$} & \multicolumn{2}{|c|}{$\begin{array}{c}\text { Child dietary diversity } \\
\text { (child 7-23 months, } \\
n \text { 864) }\end{array}$} & \multicolumn{2}{|c|}{$\begin{array}{l}\text { Maternal practice index } \\
\text { (child } 6 \text { months, } n 81 \text { ) }\end{array}$} & \multicolumn{2}{|c|}{$\begin{array}{l}\text { Maternal dietary diversity } \\
\text { (child 7-23 months, } n \text { 864) }\end{array}$} \\
\hline & $\beta$ & $P$ value & $\beta$ & $P$ value & $\beta$ & $P$ value & $\beta$ & $P$ value & $\beta$ & $P$ value & $\beta$ & $P$ value \\
\hline \multicolumn{13}{|c|}{ Frequency of exposure to $P F$ in the past 6 months } \\
\hline Once (n 236) & 0.215 & 0.107 & 0.238 & $0.001^{\star \star}$ & 0.056 & 0.664 & 0.038 & $0.045^{\star}$ & 0.460 & 0.328 & 0.041 & 0.145 \\
\hline Twice $(n 166)$ & 0.387 & $0.004^{\star *}$ & 0.213 & $0.006^{\star \star}$ & -0.155 & 0.416 & 0.028 & 0.446 & -0.059 & 0.920 & 0.065 & 0.056 \\
\hline Three or more ( $n$ 238) & 0.656 & $0.000^{\star \star \star}$ & 0.309 & $0.000^{\star \star \star}$ & -0.049 & 0.778 & 0.058 & $0.021^{*}$ & 0.616 & 0.238 & 0.064 & $0.035^{\star}$ \\
\hline Child's age (months) & 0.016 & $0.007^{\star \star}$ & -0.008 & 0.060 & NA & NA & 0.015 & $0.000^{\star \star \star}$ & NA & NA & 0.005 & $0.028^{*}$ \\
\hline Maternal age (years) & 0.001 & 0.862 & -0.010 & 0.480 & 0.008 & 0.611 & -0.001 & 0.410 & 0.049 & 0.211 & -0.002 & 0.360 \\
\hline Maternal education (range: $0-13$ years) & 0.044 & $0.000^{* * *}$ & 0.015 & $0.034^{*}$ & 0.020 & 0.141 & 0.008 & $0.021^{*}$ & 0.045 & 0.448 & 0.007 & $0.048^{*}$ \\
\hline \multicolumn{13}{|l|}{ Caste } \\
\hline Janjati & -0.250 & 0.084 & -0.401 & $0.000^{\star \star \star}$ & -0.140 & 0.529 & -0.086 & 0.060 & -0.382 & 0.668 & -0.025 & 0.567 \\
\hline Bahun/Chhetri & -0.053 & 0.597 & 0.013 & 0.860 & 0.331 & $0.020^{*}$ & 0.025 & 0.515 & 0.724 & 0.153 & -0.011 & 0.769 \\
\hline Other Madhesi Terai & 0.054 & 0.721 & 0.088 & 0.510 & -0.371 & 0.063 & -0.009 & 0.836 & 1.729 & 0.002 & -0.049 & 0.261 \\
\hline Muslim & -0.024 & 0.915 & $-0 \cdot 101$ & 0.414 & -0.644 & $0 \cdot 160$ & 0.068 & 0.492 & 3.110 & 0.050 & -0.007 & 0.924 \\
\hline Other & 0.312 & 0.085 & 0.049 & 0.795 & -0.292 & 0.343 & -0.105 & $0.029^{*}$ & $2 \cdot 870$ & 0.024 & -0.066 & 0.094 \\
\hline Asset index (range: $0-8$ ) & 0.033 & 0.384 & 0.094 & $0.002^{\star \star}$ & 0.058 & 0.564 & 0.039 & $0.000^{\star \star \star}$ & 0.113 & 0.681 & 0.039 & $0.000^{\star \star \star}$ \\
\hline \multicolumn{13}{|l|}{ Agroecological zone } \\
\hline Hill & 0.066 & 0.773 & -0.316 & $0.018^{*}$ & 0.515 & $0.006^{* *}$ & -0.022 & 0.635 & 0.395 & 0.552 & 0.131 & $0.021^{*}$ \\
\hline Terai & -0.230 & 0.184 & 0.294 & $0.005^{\star \star}$ & 0.246 & 0.056 & 0.157 & $0.000^{\star \star \star}$ & 1.316 & 0.126 & 0.122 & $0.001^{* *}$ \\
\hline
\end{tabular}

PF, peer facilitator; NA, not applicable.

Reference category for exposure to PF is none, for caste is Dalit, and for agroecological zone is mountain. Models controlled for ward-level clustering.

Child knowledge index: only breast milk should be given for 6 months, fruits and vegetables, and animal-source foods are good for child aged 6-23 months.

Maternal knowledge index: a pregnant woman should eat one extra meal, lactating woman should eat two extra meals and pregnant woman should take iron and folic acid supplements for $180 \mathrm{~d}$.

Child practice index (child 6 months): child given colostrum and breast-fed within $1 \mathrm{~h}$.

Child dietary diversity (child $7-23$ months): dietary diversity (0-7 food groups).

Maternal practice index (child 6 months): dietary diversity (0-9 food groups), ate two extra meals while lactating, received three postnatal care check-ups, took iron and folic acid supplements for at least $45 \mathrm{~d}$ post-delivery. Maternal dietary diversity (child 7-23 months): dietary diversity (0-9 food groups)

${ }^{\star} P<0.05,{ }^{\star *} P<0.01,{ }^{\star \star *} P<0.001$. 
$P=0.004$; three or more times: $\beta=0.656, \quad P<0.001$ ). Similarly, in adjusted analyses, exposure to a $\mathrm{PF}$ in the previous 6 months was also associated with higher maternal nutrition knowledge (once: $\beta=0 \cdot 238, P=0 \cdot 001$; twice: $\beta=0.213, P=0.006$; three or more times: $\beta=0.309$, $P<0 \cdot 001)$. PF exposure frequency among mothers of older children (i.e. 7-23.9 months) was associated with a small improvement in dietary diversity scores and this increase was significant for once $(\beta=0.038, P=0.045)$ or three or more times $(\beta=0.058, P=0.021)$ in adjusted analyses. A similar association pattern between PF exposure and slightly higher maternal dietary diversity scores was observed for mothers of older children, compared with mothers with no PF exposure (three or more: $\beta=0.064, P=0.035)$.

\section{Discussion and conclusions}

Exposure to a PF for up to 1 year modestly improved several maternal and child knowledge and practice indicators compared with a comparison group with no PF exposure, in districts already receiving other inputs, including counselling and nutrition information, through the Suaahara programme. The double difference estimates were significant for five indicators: (i) knowing that fruits and vegetables are good for children aged 6-23.9 months; (ii) child dietary diversity; (iii) child minimum dietary diversity ( $\geq 4$ of 7 food groups); (iv) maternal dietary diversity; and (v) maternal minimum dietary diversity ( $\geq 4$ of 9 food groups). Frequency of exposure to a PF in the past 6 months was positively associated with the following maternal and child knowledge and practices: (i) child nutrition knowledge index score for those who had met a PF twice or three or more times; (ii) maternal nutrition knowledge index score for those who met the PF once, twice, or three or more times; (iii) diet diversity among children aged 7-23.9 months who met the PF once or three or more times; and (iv) diet diversity of mothers of children aged 7-23.9 months who met the PF three or more times. For most indicators, improvements were also observed in the comparison group. This was expected because both PF and comparison VDC received Suaahara's core interventions, which promoted similar nutrition messages and behaviours.

Our findings show that maternal exposure to a PF had an impact on maternal and child diets. Although there were few differences in maternal knowledge regarding MIYCN, the mean diet diversity score and percentage of mothers and children who ate at least four out of seven food groups in the past $24 \mathrm{~h}$ were significantly higher in the PF group compared with the comparison group. First, the result that peer mobilization improved child nutrition is similar to that found by a small but growing body of literature on improvements in breast-feeding, and timely initiation of complementary feeding, as a result of exposure to peer educators ${ }^{(16,19)}$. Our findings show that in addition to breast-feeding and initiation of complementary feeding, peers can also be mobilized to improve the variety of maternal and child diets. Second, the results show that the PF had an added effect. The finding that multiple interventions can have an additive effect is similar to findings from Alive $\&$ Thrive programme in Bangladesh, which showed that three intervention platforms together increased mothers' knowledge on complementary feeding and child dietary diversity, compared with any of the interventions alone or even two of the interventions together ${ }^{(3)}$. Diversifying the diet for the mother and child is important because it increases the likelihood of higher quality or, in other words, nutrient adequacy of the diet ${ }^{(23)}$. The quality of the mother's diet is crucial for her own health as well as for her child's because women have increased nutrient needs during pregnancy and lactation. Even though we saw improvements in maternal and child diets, less than half were meeting minimum dietary diversity standards, which suggests that further interventions are required. Translation of knowledge into practices may be limited by availability of food, thus efforts need to be made to improve both availability and affordability of diverse foods.

Our findings also show that frequency of contact with a PF may be a key element of the PF's success. Any exposure to a PF increased maternal nutrition knowledge but only exposure to a PF two or more times increased child nutrition knowledge. Among children aged 7-23.9 months, respondents who had met the PF once had improved child diet diversity score. Both child and maternal dietary diversity scores were higher when respondents met the PF at least three times in the past 6 months. Our results provide further evidence on the importance of frequency of contact, as shown by an evaluation in Mozambique where improvements in child nutrition were observed when more than $90 \%$ of the respondents had met a care group volunteer in the past 2 weeks $^{(24)}$. One reason why we may not have found any changes in practice indicators for children 6 months of age may be due to the small sample size ( $n$ 81) and hence lack of power to detect a change. Changes in almost all maternal and child nutrition indicators were higher in the PF group compared with the comparison group.

Our study also had a few unusual findings and we have attempted to provide explanations for them. The comparison group did particularly worse on the indicator of mothers eating two meals more than usual while lactating $(-12.7$ percentage points). This may have been due to the slight delay in data collection resulting from the earthquake of April 2015 and the endline survey being conducted in part during the lean period. It is possible that lactating women in the comparison group coping with low food supplies at home during the lean season did not adopt this practice in the absence of a reminder from the $\mathrm{PF}$. Since the PF and comparison VDC were within the same district, we do not think differences in harvest, and 
thus food availability between the two groups, could explain this result. We were surprised that the change in knowledge about the need to eat an additional meal during pregnancy was higher in the comparison areas than in the PF intervention areas. This may be due to women in comparison areas having heard this message more recently, and thus remembering and reporting it, than women from areas with a PF. PF promoted the same core nutrition knowledge and behaviour messages as other Suaahara interventions and thus there is no reason to have expected this difference.

In terms of maternal health-service utilization, the number of women who received four or more antenatal care services in PF areas was low (53\%), which is lower than what has been found in recent nationally representative surveys $(69 \%)^{(10)}$. The same survey also showed that most mothers in rural areas do not receive postnatal care during the recommended time ${ }^{(10)}$. Provision of iron and folic acid is a key component of antenatal care and postnatal care; however, knowledge of and consumption of iron and folic acid by our respondents during pregnancy and lactation were poor. This is not surprising, given that only $42 \%$ of pregnant women take iron and folic acid for at least $180 \mathrm{~d}$ nationally ${ }^{(10)}$. Health-serviceseeking behaviours are difficult to change because they are not only driven by improvements in knowledge around those behaviours, but also resources including finances or time. Furthermore, in Nepal, women's autonomy has been associated with receiving the recommended number of antenatal care check-ups ${ }^{(25)}$. This suggests that programmes aiming to increase health-service utilization among women should not only rely on increasing knowledge but should also aim to facilitate her decisionmaking control regarding her own health.

There are a number of limitations to our study. First, the comparison group also received Suaahara's core intervention package, making it difficult to disentangle the impact of the PF. The core intervention package included MIYCN, maternal and child health and family planning, and water, sanitation and hygiene. Similarly, Nepal is saturated with nongovernmental organizations and development partner health and nutrition programmes, which may have been running in Suaahara districts. However, we did not have any reason to expect there to be differences in sub-district areas with and without PF. For this reason, in the present study we compared similar Suaahara intervention areas which differed only in whether the intervention included a PF or not and assessed the added value of the PF. Second, we were unable to control for sex of the child and other additional household dynamics in the regression models given limitations of the data set, despite our awareness that these additional factors may have been important covariates. Third, our study design may not have captured the full impact of the PF approach, both because of small disaggregated sample sizes and because the exposure duration between baseline and endline was only 12 months. Thus, it is likely that our study underestimates the potential effect of a PF approach for improving maternal and child nutrition-related knowledge and practices. Fourth, the study is representative only of the three districts which had both a baseline and endline survey; additional studies are needed to examine the effectiveness of the PF approach in other areas of Nepal and other countries. Finally, we are also not able to address questions around the sustainability of this model given the present study's research objectives, although we do acknowledge that other than PF suitability and motivation for this type of work, consideration must be given to the opportunity costs of engaging in this type of community work including time, income or childcare foregone.

Despite these limitations, the results are quite promising for the role peer mobilization can play in improving MIYCN-related knowledge and practices in hard-to-reach areas of Nepal. PF may complement the work done by FCHV to reach children and pregnant and lactating women, and may be a sustainable approach given the emerging realization that FCHV need to be supported to identify disadvantaged households and provide tailored services to them. However, at a time when large investments are being made to address maternal and child undernutrition in Nepal, interventions such as the PF approach may prove to be effective and enable Nepal to continue reductions in stunting and maternal and child underweight that have been happening since the mid$1990 s^{(26)}$. Particularly, findings from the present study may be useful for the development of the National Strategy for Reaching the Unreached to Reduce Health and Nutrition Inequities in Nepal. Therefore, maternal and child nutrition policies and programmes designed and implemented in Nepal and globally should consider the role peer mobilizers can play in improving MIYCN-related knowledge and practices. Future studies should aim to capture the experiences and factors motivating peers to promote MIYCN messages, as well as the effect of increased (greater than 12 months) exposure to PF on MIYCN knowledge and practices.

\section{Acknowledgements}

Acknowledgements: The authors would like to acknowledge the women of Bajhang, Bhojpur and Rupandehi for their participation in the study; VARG for data collection and management; and Suaahara-affiliated researchers for reviewing numerous manuscript drafts as well as Suaahara Phase I implementing partners: Save the Children, Helen Keller International, Johns Hopkins Bloomberg School of Public Health Center for Communication Programs, JHPIEGO, Nutrition Promotion and Consultancy Services, Nepal Water for Health, and Nepali Technical Assistance Group. Financial support: Suaahara Phase I, funded by the US Agency for International Development (USAID) Cooperative Agreement AID-367-A-11-00004, provided financial support for this survey. This study is made 
possible by the generous support of the American people through USAID. The contents are the responsibility of A.S. and co-authors and do not necessarily reflect the views of USAID or the US Government. Conflict of interest: All co-authors previously worked for Suaahara Phase I or are currently involved with Suaahara Phase II. Authorship: A.S. and K.C. developed the research question and analysed the data. A.S., K.C., R.D.W.K. and G.M. interpreted results and drafted and revised the manuscript. A.S., P.P.R. and B.P. designed the evaluation. P.P.R. and B.P. provided support during data collection and reviewed manuscript drafts. All authors read and approved the final manuscript. Ethics of human subject participation: Ethical approval for the evaluation was obtained from the Nepal Health Research Council (NHRC) and all respondents gave their informed verbal consent to participate in both survey rounds.

\section{References}

1. Bhutta ZA, Lassi ZS, Pariyo G et al. (2010) Global Experience of Community Health Workers for Delivery of Health Related Millennium Development Goals: A Systematic Review, Country Case Studies, and Recommendations for Integration into National Health Systems, pp. 249-261. Geneva: WHO and Global Health Workforce Alliance.

2. Mason JB, Sanders D, Musgrove P et al. (2006) Community health and nutrition programs. In Disease Control Priorities in Developing Countries, 2nd ed., pp. 1053-1074. Washington, DC: International Bank for Reconstruction and Development/World Bank.

3. Menon P, Nguyen PH, Saha KK et al. (2016) Combining intensive counseling by frontline workers with a nationwide mass media campaign has large differential impacts on complementary feeding practices but not on child growth: results of a cluster-randomized program evaluation in Bangladesh. J Nutr 146, 2075-2084.

4. New ERA (2007) An Analytical Report on National Survey of Female Community Health Volunteers of Nepal. Kathmandu: USAID/Government of Nepal.

5. Central Bureau of Statistics (2012) Nepal Population and Housing Census. Kathmandu: Central Bureau of Statistics, National Planning Commission Secretariat, Government of Nepal.

6. Ministry of Health and Population (2010) National Female Community Health Volunteer Program Strategy: Unofficial Translation. Kathmandu: Ministry of Health and Population and USAID.

7. Advancing Partners \& Communities (2015) Female Community Health Volunteer (FCHV) National Survey Report. Arlington, VA: Advancing Partners \& Communities.

8. Fiedler JL (2000) The Nepal National Vitamin A Program: prototype to emulate or donor enclave? Health Policy Plan 15, 145-156.

9. Headey DD \& Hoddinott $J$ (2015) Understanding the rapid reduction of undernutrition in Nepal, 2001-2011. PLoS One 10, e 0145738 .
10. Ministry of Health, New ERA \& ICF (2016) Nepal Demographic and Health Survey 2016: Key Indicators. Kathmandu: Ministry of Health, Nepal.

11. Ministry of Health and Population (2009) Health Sector Gender Equality and Social Inclusion Strategy. Kathmandu: Ministry of Health, Nepal.

12. Cunningham K, Singh A, Pandey Rana P et al. (2017) Suaahara in Nepal: an at-scale, multi-sectoral nutrition program influences knowledge and practices while enhancing equity. Matern Child Nutr 13, issue 4, doi: 10.1111/ mcn.12415.

13. Dulal B, Mundy G, Sawal R et al. (2017) Homestead food production and maternal and child dietary diversity in Nepal: variations in association by season and agroecological zone. Food Nutr Bull 38, 338-353.

14. Sokol R \& Fisher E (2016) Peer support for the hardly reached: a systematic review. Am J Public Health 106, e1-e8.

15. Chapman DJ, Morel K, Anderson AK et al. (2010) Breastfeeding peer counseling: from efficacy through scale-up. J Hum Lact 26, 314-326.

16. Pérez-Escamilla R, Hromi-Fiedler A, Vega-López $\mathrm{S}$ et al. (2008) Impact of peer nutrition education on dietary behaviors and health outcomes among Latinos: a systematic literature review. J Nutr Educ Behav 40, 208-225.

17. Haider R \& Saha KK (2016) Breastfeeding and infant growth outcomes in the context of intensive peer counselling support in two communities in Bangladesh. Int Breastfeed J 11, 18.

18. Fabrizio CS, Liere M \& Pelto G (2014) Identifying determinants of effective complementary feeding behaviour change interventions in developing countries. Matern Child Nutr 10, $575-592$.

19. Vandana S \& Jain PS (2014) Effectiveness of peer-counseling for promoting optimal complementary feeding practices among infants belonging to urban slums of Delhi. Int J Med Res Health Sci 3, 289-296.

20. Mahat G, Scoloveno MA \& Ayres C (2011) HIV/AIDS knowledge and self-efficacy among Nepalese adolescents: a peer education program. Res Theory Nurs Pract 25, 271-283.

21. World Health Organization (2010) Indicators for Assessing Infant and Young Child Feeding Practices: Part 2: Measurement. Geneva: WHO.

22. Kennedy G, Ballard T \& Dop MC (2011) Guidelines for Measuring Household and Individual Dietary Diversity. Rome: FAO.

23. UNICEF (1990) Strategy for Improved Nutrition of Children and Women in Developing Countries. New York: UNICEF.

24. Davis TP, Wetzel C, Avilan EH et al. (2013) Reducing child global undernutrition at scale in Sofala Province, Mozambique, using care group volunteers to communicate health messages to mothers. Glob Health Sci Pract 1, 35-51.

25. Adhikari R (2016) Effect of women's autonomy on maternal health service utilization in Nepal: a cross sectional study. BMC Womens Health 16, 26.

26. Cunningham K, Singh A, Headey D et al. (2016) Reaching new heights: 29 years of nutrition progress in Nepal. In Nourishing Millions: Stories of Change in Nutrition, pp. 115123 [S Gillespie, J Hodge, S Yosef et al., editors]. Washington, DC: International Food Policy Research Institute. 